\title{
Comparison of Chinese and Foreign Cultural Images in the Process of Translation
}

\author{
Sun Yanbo \\ Xi'an Peihua University, Xi'an, China
}

Keywords: Cultural images, Trans placement, Disposal

\begin{abstract}
By criticizing semiotical theory in translation, this paper discusses the translation of cultural images. It advocates that the cultural images in original text ought to be retained during translating process, depending on specific textual style.
\end{abstract}

\section{Introduction}

Nida said: “Translation means translating meanings.” It's a brief conclusion, but it's difficult to realize it. This is a translation perspective based on semiotics, which believes that translation is the process of transferring meaning through the transformation between different symbolic systems. The semiotic scientist Morris proposed three relations in symbolic process: the relationship between symbol and object, the relationship between symbol and interpreter, and the relationship between symbols. Correspondingly, there are three kinds of semiotic meanings: referential meaning, pragmatic meaning and internal meaning. For example, notional words have referential meaning, and function words have internal meaning. The combination of words into sentences, the combination of sentences into paragraphs and the combination of paragraphs into articles result in the sum of two or three of internal meaning, referential or pragmatic meaning. These meanings in the original text must be faithfully transplanted to the translation. Therefore, the principle of translation proposed by semiotics is translation means translating meanings.

As we all know, language is the carrier of culture. Due to the different cultures, there are often three types of relations between the original language and the target language: complete equivalence, partial equivalence and non-equivalence. For example, "he is a fox" is basically completely equivalent to “他是一只狐狸”; “she is a cat” is partly equivalent to “她是一只猫”; “我 们是龙之子” isn't equivalent to “we are the sons of dragon.” To convey these meanings in translation, we must be very cautious if we obey the principle that "translation means translating meanings". Therefore, semiotics puts forward a special supplement: in translation, the translation should reflect the original social and cultural factors in order to avoid the loss of meaning.

\section{The Concept of Cultural Image}

The increasing frequency of cultural exchange puts forward higher and higher requirements on translation. Today, the translation should convey the purpose, be beautiful and smooth and convey the original cultural image as accurately as possible. For example, John Turner translated Li Bai’s eternal verse “烟花三月下扬州” into “mid-March mists and blossoms go”. As the phrase “扬州 (Yangzhou)" is not translated, the rich meaning and the beautiful artistic conception of the original poem are greatly affected. Here, “扬州 (Yangzhou)” is a typical cultural image. For ancient Chinese literati, “扬州” is by no means a simple place name. It represents a scenic spot and an ideal and ecstatic place for entertaining scholars and writers. "Mid-March" is the most beautiful spring time to go to “扬州 (Yangzhou)", a bustling land of flowers. “Time” and "place” are both indispensable.

However, the awareness of cultural images so far is not sufficient. People tend to separate the image from culture, regard it as a kind of rhetorical device and put it together with figurative words, allusions, idioms, metaphors and proverbs. There is no doubt that cultural images and figurative 
words are intimately related to each other, but they are still different from each other: cultural images permeate these words but contain broader and deeper connotations.

Cultural images embody the crystallization of the social culture of all ethnic groups. A considerable part of them are also closely related to the legends and totems in the early days of various social and ethnic groups. In the long historical years, they continue to appear in the language, slowly form cultural symbols and have relatively fixed and unique cultural implications.

\section{The Manifestation of Cultural Images}

They can be plants, such as pine, plum, bamboo, orchid and chrysanthemum in Chinese, and oak, olive, birch and rose in European and American languages.

They can be specific or legendary birds and beasts, such as crow, magpie, dragon, unicorn in Chinese, and owl, lion and bear in European and American languages.

They can be proverbs, idioms, allusions or the images or metaphorical objects of figurative words, such as “画蛇添足 (gild the lily)” and “三个臭皮匠顶个诸葛亮 (two heads are better than one)" in Chinese, and "to put a fifth wheel to the coach" and "all roads lead to Rome" in European and American languages. Here, “蛇足”, “诸葛亮”, “a fifth wheel” and “Rome” all have their specific meanings and become cultural images.

They can even be numbers, such as “三 (three)” and “八 (eight)” in Chinese, and “seven” and “thirteen” in European and American languages. The “三” here means “many”, such as “三思而行 (think twice)”; “八” sounds like “发”, so it means “developed” and “rich”; in English, “seven” also means "many". For example, if we want to describe the magnitude, we can say "at seven-league strides"; in western languages, "thirteen” is considered an unlucky number.

\section{The Misplacement of Images}

Different ethnic groups often form their unique cultural images because of their respective living environment and cultural traditions. For example, camel is a symbol of strength in Arabia, elephant is a symbol of auspiciousness in India, and cattle is a symbol of industry in China. These cultural images generally do not constitute a problem in translation. However, there are some cultural images that are common to several ethnic groups but are given different or even opposite meanings. In one language, something commendatory and positive becomes derogatory and counter-productive in another language; or, if not the opposite, they're at least quite different. The same objective phenomenon that various groups of people in the world see is painted with different colors in different national languages. This is the misplacement of cultural images.

For example, “龙 (dragon)” has this image in English and Chinese cultures. In Chinese culture, “龙” represents the emperor, being a symbol of noble and holiness. Many of the words related to “龙” have noble and holy meanings, such as “真龙天子 (the emperor)”, “龙颜 (the emperor)”, “龙 袍 (the imperial robe)” and “望子成龙 (have great ambitions for one’s child)”. However, in English culture, dragon is a cruel monster and a terrible symbol, so the British ancient heroic epic "Beowulf" tells the heroic achievement of killing the dragon. When the Chinese proudly say that they are "descendants of the dragon", what should the British think? I am afraid that they may not be able to appreciate the pride.

For another example, in Chinese culture, “狗 (dog)” is being despised and cursed. Almost all dog-related words are derogatory, such as “狗胆包天 (monstrous audacity)”, “狗急跳墙 (a dog will leap over a wall in desperation)”, “狗仗人势 (like a dog threatening people on the strength of its master's power)” and “狗嘴里吐不出象牙 (a filthy mouth cannot utter decent language)”. On the contrary, in Western culture, dog is man's good friend. When someone is lucky, he says "I am a lucky dog", but when someone feels he is old and can not learn new things, he will say "I'm too old a dog to learn new tricks". The proverb "every dog has its day" means "everyone can be successful one day", which is not derogatory. The proverb "give a dog a bad name and hang him to death" 
means "if you are out to condemn someone, you can always trump up a charge". The sympathy is clearly showed.

These are all the first type of cultural misplacement. The reasons are mostly related to the geographical environments, living customs and cultural traditions of various ethnic groups. Among them, the difference in cultural traditions is the most important reason. Long-standing folklore, myths, historical events and the accumulation of literary works are the reasons for the misplacement of cultural images of various ethnic groups.

The second type of misplacement of cultural images is manifested as the differences in images as metaphorical objects. This situation is reflected in idioms and proverbs. Such images don't have too much cultural accumulation, but they are given specific meanings in specific language situations as metaphorical objects in metaphor mostly. For example, to describe someone is thin, the Chinese say "he is as thin as a monkey", while English speakers say "he is as thin as a shadow". To describe someone is poor, the Chinese say "he is as poor as a beggar", while English speakers say "he is as poor as a church mouse”. In proverbs, the "misplacement" of images as metaphorical objects is seen more frequently. To describe everything is due, the Chinese say “无风不起浪 (there are no waves without wind)”, while English speakers say “no smoke without fire”; “艄公多了砸烂船” in Chinese means "too many people will mess things up", while English speakers say "too many cooks spoil the broth”.

Actually, even the images of idioms and proverbs as metaphorical objects always carry the cultural characteristics of particular nations, but they're sometimes obvious and sometimes obscure. For example, “when in Rome, do as the Roman do” in English can of course be translated as “入乡 随俗”, but the original cultural color is lost; it seems pretty good to translate "talk of the devil, and he is sure to appear” as “说到曹操曹操就到”, but “曹操” is a historical figure with the cultural color of our nation, so the translation will undoubtedly lead readers to the wrong association.

\section{Cultural Image Processing}

The dislocation of cultural images presents a topic worthy of study in translation. Nida said: “Translation means translating meanings". This is true, but in the translation of cultural images, the translators are often confused. This is because cultural images generally have both superficial and deep meanings. For example, if “三个臭皮匠,顶个诸葛亮” is translated as “Even three common cobblers can surpass Zhuge Liang”, it conveys the surface meaning of the proverb, but does not show its deep meaning; if it is translated as "Many heads are better than one" or "Collective wisdom is greater than a single wit", it has translated its deep meaning, but has lost the unique cultural images in Chinese, namely "cobblers" and "Zhuge Liang." In the original text, the harmonious combination of language of image and meaning has to be split in the translation, which often puts the translators in a double squeeze and leads to the loss and distortion of the cultural image.

In the translation of poetry, there are many examples of such lost and distorted cultural images. However, according to the translation theories of semiotics, this difference is allowed. In the process of translation, the principle of "allowing difference" has concealed numerous cultural images. Here, we point out the loss and distortions of cultural images. Our purpose is not to blame or criticize a person or a certain text, but to use "cultural images" to generalize a phenomenon in the original language and to bring up the transmission of cultural images specifically for discussion. At present, the domestic translation circle touches on the transfer of cultural images from the following three aspects:

\subsection{Image transmission is discussed as a translation technique}

Such studies mainly focus on the translation studies of idioms, proverbs, allusions and figurative words, which are highly practical and the methodology is nothing more than the "same old three theories": literal translation, free translation, combination of literal translation and free translation. 


\subsection{The translation of figurative words is discussed from the linguistic perspective}

Such studies suggest that "figurative words in any language are a rhetorical device that gives the readers a vivid and deep impression, that is, it can enhance the influence on the readers' mental activity", and think that the translation of figurative words should evoke the readers' "memory of the perception of objective things that exists in the brain" and stimulate them "to associate this with that so as to create creative imagination".

\subsection{The understanding and expression of certain cultures, concepts, allusions, proverbs, etc. are studied from the perspective of cultural contrast}

Tan Zhaixi pointed out in his article Culture Comparison and Translation that the differences in cultural personalities between different ethnic groups led to such phenomena as "vocabulary vacancy" and "vocabulary conflict". For example, in European and American languages, there is no “白喜事” out of “红白喜事” in Chinese. Although the Chinese language has “玉帝”, it is not equal to "God" in European and American languages. Therefore, the translator must correctly identify and express the similarities and differences in culture before translating. For example, when translating foreign allusions, it is not necessary to put a Chinese label on them and convert them into "national products”. Otherwise, “Jupiter” will be translated as “玉帝”, “Hera” as “王母娘娘” and “Cupid” even as “红娘”, which is so ridiculous!

The specific methods for conveying cultural images are diverse and vary from person to person in the translation circle. I think there are three principles worth mentioning: the translators' professional ethics, that is, they should not be satisfied with the general meaning of the transmission of the original cultural image, but should convey the original cultural image as completely as possible; the readers' trust, that is, today's readers are not only able to accept a variety of cultural image of a foreign culture, but also more and more interested in the foreign cultural images, so the translators don't need to translate the bread as “馒头” for the readers; case by case, that is, the translators should give full consideration to the acceptability of possible readers. If the readers' cultural level is low and it is necessary to explain, then the method of literal translation and annotation may be adopted.

\section{Conclusion}

The question of how to transmit cultural images sometimes pushes the translators into a place where they can't have their cake and eat it too. However, we must face the difficulties, and keep thinking about it. We should offer the essence of the original text to our readers as completely as possible with our creative work so that readers will not only enjoy the delicacy of translation, but also enjoy the essence of the original text.

\section{References}

[1] Fang Mengzhi,Translation Studies and Practice[M],Qingdao,Qingdao Publishing House,2009

[2] Lliu Miqing, Contemporary Translation Theories[M], Taipei, Shu Lin Publishing House, 2005

[3] Luo Xinzhang, Translation Studies, Beijing, Commercial Press, 2014

[4] Yang Zijian, Liu Xueyun,A Series of Translation Studies in China[M] Wuhan, Hubei Education Press,2014

[5] Nida, Engene 2012 Theory and Practice of Translation [M] Leiden: E.J.Brill 